Provided for non-commercial research and education use. Not for reproduction, distribution or commercial use.

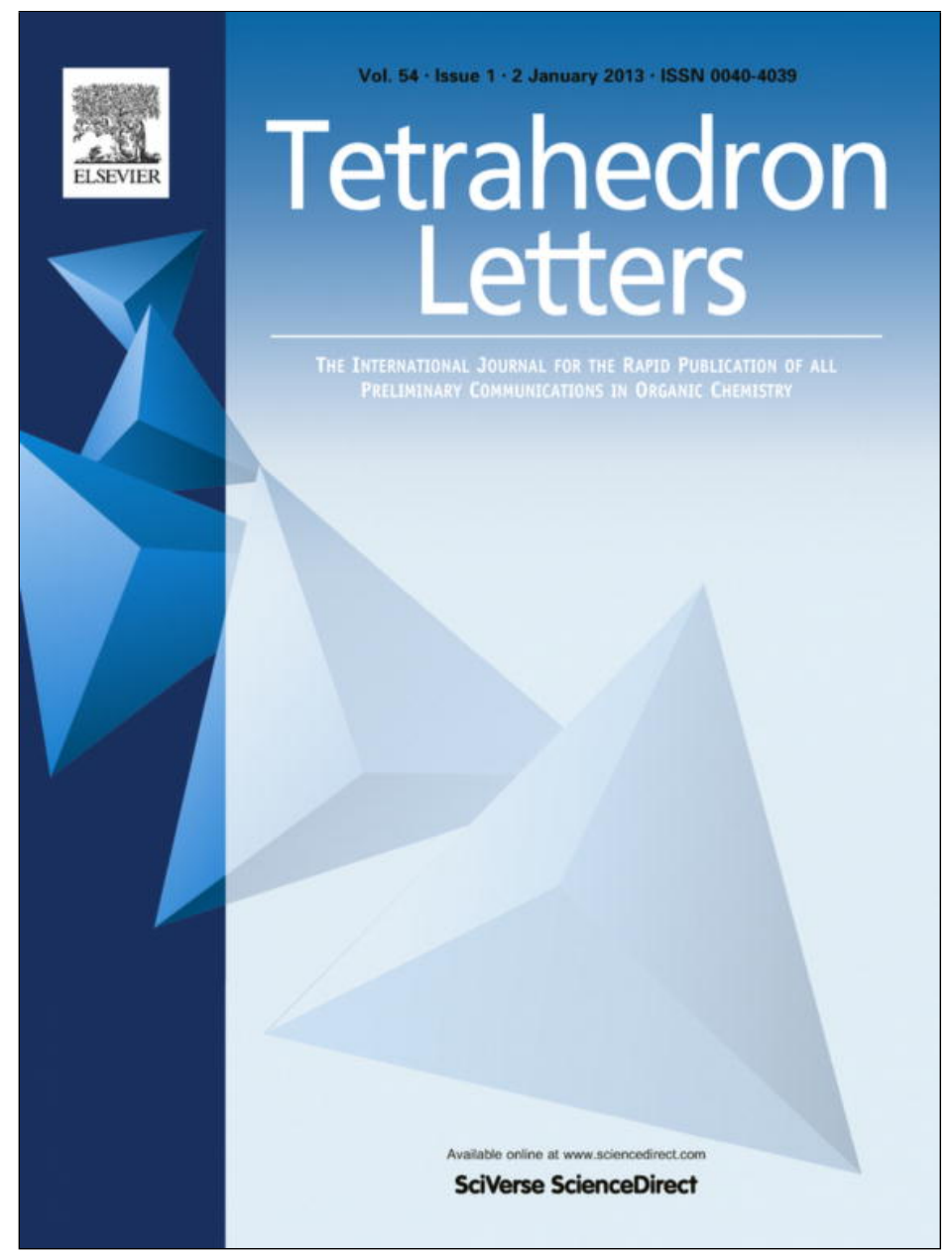

This article appeared in a journal published by Elsevier. The attached copy is furnished to the author for internal non-commercial research and education use, including for instruction at the authors institution and sharing with colleagues.

Other uses, including reproduction and distribution, or selling or licensing copies, or posting to personal, institutional or third party websites are prohibited.

In most cases authors are permitted to post their version of the article (e.g. in Word or Tex form) to their personal website or institutional repository. Authors requiring further information regarding Elsevier's archiving and manuscript policies are encouraged to visit:

http://www.elsevier.com/copyright 


\title{
Electrochemical characterization of bioactive hydroxyxanthones by cyclic voltammetry
}

\author{
Clementina M. M. Santos ${ }^{\mathrm{a}, *}$, M. Beatriz Q. Garcia ${ }^{\mathrm{b}}$, Artur M. S. Silva ${ }^{\mathrm{c}}$, René Santus ${ }^{\mathrm{d}, \mathrm{e}}$, Patrice Morlière ${ }^{\mathrm{e}, \mathrm{f}, \mathrm{g}}$, \\ Eduarda Fernandes $\mathrm{b}, *$ \\ ${ }^{a}$ Department of Vegetal Production and Technology, School of Agriculture, Polytechnic Institute of Bragança, 5301-855 Bragança, Portugal \\ ${ }^{\mathrm{b}}$ REQUIMTE, Department of Chemical Sciences, Faculty of Pharmacy, University of Porto, Rua de Jorge Viterbo Ferreira No. 228, 4050-313 Porto, Portugal \\ ${ }^{\mathrm{C}}$ Department of Chemistry \&' QOPNA, University of Aveiro, 3810-193 Aveiro, Portugal \\ ${ }^{\mathrm{d}}$ Muséum National d'Histoire Naturelle, Département RDDM, F-75231 Paris, France \\ e CHU Amiens, Laboratoire de Biochimie, F-80054 Amiens, France \\ ${ }^{\mathrm{f}}$ INSERM, U1088, F-80054 Amiens, France \\ ${ }^{\mathrm{g}}$ Université de Picardie Jules Verne, Faculté de Médecine et de Pharmacie, F-80036 Amiens, France
}

\section{A R T I C L E I N F O}

\section{Article history:}

Received 1 October 2012

Revised 19 October 2012

Accepted 23 October 2012

Available online 30 October 2012

\section{Keywords:}

Xanthones

Cyclic voltammetry

Scavenging activity for ROS and RNS

Catechol

Glassy carbon

\begin{abstract}
A B S T R A C T
The present study reports the electrochemical behavior of several phenolic and catecholic-substituted 2,3-diarylxanthones on a glassy carbon electrode, challenged by cyclic voltammetry at different $\mathrm{pH}$ values $(4.0,7.4$, and 11.0). Higher $\mathrm{pH}$ values required lower anodic and cathodic peak voltages. The oxidation of catecholic groups occurred at lower peak potentials in a reversible and $\mathrm{pH}$ dependent manner. Anodic peak potentials appeared at higher $\mathrm{pH}$ values and were attributed to the electrochemically irreversible oxidation of the phenolic groups. The number and position of hydroxyl substituents were the determinants for the electrochemical behavior and found to correlate with the scavenging activity for reactive oxygen (ROS) and nitrogen species (RNS). A xanthone with two catechol units presented the lowest anodic potential voltage $\left(E_{\mathrm{pa}}=0.15 \mathrm{~V}\right)$ and proved to be the most effective ROS and RNS scavenger.
\end{abstract}

(c) 2012 Elsevier Ltd. All rights reserved.
Xanthones are redox-active compounds with a tricyclic scaffold, identified in some higher plants, with most of the derivatives restricted to the Guttiferae and Gentianaceae families. Several derivatives can also be isolated from a variety of fungi and lichens. ${ }^{1}$ These compounds are highly diverse in their chemical structure, including simple oxygenated and prenylated substituents, or appearing as more complex frameworks as xanthonolignoids or bis-xanthones. ${ }^{1,2}$ Naturally occurring analogues exhibit several biological and pharmacological properties such as anti-allergic, antiinflammatory, antimalarial, antimicrobial, and antitumour activities and also play an important role in the inhibition of several enzymes. ${ }^{3}$

Studies on the antioxidant activity of both natural and synthetic xanthones have provided interesting results, including: (i) scavenging activity against reactive oxygen species (ROS) and reactive nitrogen species (RNS), (ii) inhibition of pro-oxidant enzymes, and (iii) metal chelating capacity. ${ }^{3-5}$ Structure/activity studies of phenolic compounds revealed that the number and position of hydroxyl substituents in their skeleton are features of great importance for a high antioxidant activity. ${ }^{6}$

\footnotetext{
* Corresponding authors. Tel.: +351 273303308; fax: +351 273325405 (C.M.M.S.); tel.: +351 220428673; fax: +351 222004427 (E.F.).

E-mail addresses: clems@ipb.pt (C.M.M. Santos), egracas@ff.up.pt (E. Fernandes).
}

In a previous work, concerning the putative scavenging effects of several hydroxylated xanthones against ROS and RNS, it was demonstrated that compounds with a catechol motif were the most effective scavengers, in some cases being more active than natural xanthones. ${ }^{7,8}$ In other chemical assays, involving human blood LDL and human skin keratinocytes, we could also establish structure-activity relationships. ${ }^{9}$ From these studies, it may be predicted that the investigation of the redox potential of hydroxylated xanthones can provide valuable insights into the pharmacological properties of these molecules.

Electrochemical methodologies have been successfully used to establish correlations between structure, oxidation potential, and biological activity of electroactive species. Their operating simplicity, higher sensitivity, short time of analysis, and lower reagent consuming as well as lower costs are some advantages presented by these techniques compared with chromatographic or spectroscopic methods. ${ }^{10,11}$ Thus cyclic voltammetry (CV) has become an important and widely used electroanalytical technique in many relevant studies of redox processes, in organic and inorganic chemistry, to clarify the electrochemical behavior of complex chemical and biochemical systems, and to obtain information about all types of interfacial processes depending on electrochemical currents. ${ }^{12}$ The aim of the present study is to study the electrochemical 


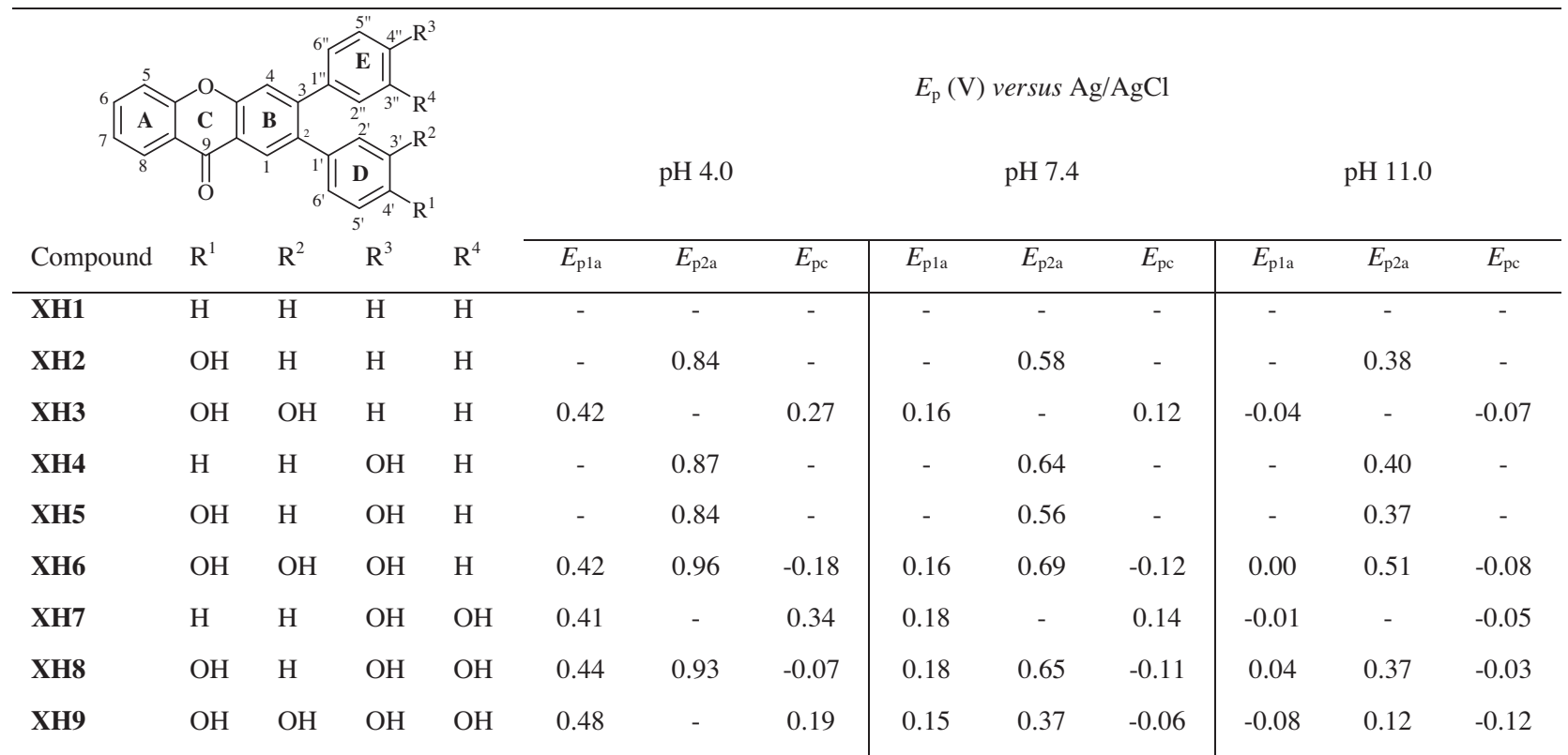

Scheme 1. Chemical structures and anodic and cathodic potentials of 2,3-diarylxanthones XH1-XH9.

behavior of a group of phenolic and catecholic-substituted 2,3diarylxanthones ${ }^{13}$ (Scheme 1 ), in aqueous solution, by cyclic voltammetry, ${ }^{14}$ and compare the obtained results with their scavenging activities for ROS and RNS.

In order to simulate the physiological conditions, the cyclic voltammograms were performed at $\mathrm{pH} 7.4$ (sodium phosphate). Assays were also performed under acidic and basic conditions, using acetate $(\mathrm{pH} 4.0)$ and carbonate-bicarbonate ( $\mathrm{pH} 11.0)$ buffers, respectively. The study on the electrochemical behavior of xanthone XH1 was limited by its solubility, which only permitted a final concentration of $0.05 \mathrm{mM}$, and no detectable peaks were found in the cyclic voltammograms, for all tested $\mathrm{pH}$ values (Scheme 1). This limitation did not allow to investigate the influence of the 2,3-diphenylxanthone motif in the electrochemical behavior of the studied xanthones XH2-XH9. Masek et al. ${ }^{15}$ performed the cyclic voltammogram of the parent xanthone at $1 \mathrm{mM}$ and detected three oxidation peaks. In that study, the cyclic voltammogram of the parent flavone at $1 \mathrm{mM}$ showed two oxidation peaks with higher potential values. These results indicate that the xanthone oxidation occurs at lower oxidation potentials, compared to the flavone, an important feature to enhance the welldocumented antioxidant ability of xanthone-type compounds. ${ }^{4,5}$

By increasing $\mathrm{pH}$ values, the anodic and cathodic peak voltages of hydroxylated xanthones XH2-XH9 decrease, similarly to that reported by other authors for several phenolic compounds. ${ }^{16-19}$ At $\mathrm{pH}$ 7.4, compounds $\mathbf{X H 2}$ and $\mathbf{X H 4}$ (final concentration of $0.05 \mathrm{mM}$ ) presented voltammograms with a single irreversible oxidation peak at $0.58 \mathrm{~V}$ and $0.64 \mathrm{~V}$, respectively (Scheme 1 ). The cyclic voltammetric profile of these compounds is similar to that observed in para-substituted flavonoids. In fact, genistein, a 4 '-hydroxyisoflavone, has a comparable oxidation peak $(0.51 \mathrm{~V})$ with that of XH2 and apigenin, the corresponding $4^{\prime}$-hydroxyflavone, presented the same oxidation peak $(0.64 \mathrm{~V})$ of $\mathbf{X H 4}$ at pH 7.4 versus $\mathrm{Ag} / \mathrm{AgCl}{ }^{20}$ Cyclic voltammograms of several hydroxybenzoic and hydroxycinnamic acids also presented single anodic peaks at higher potentials and the absence of a cathodic peak in the reverse scan. ${ }^{21}$ Moreover, the rapid decrease of the oxidation peak after multiple cyclic scans, without polishing the electrode between the cycles, clearly indicates that $\mathbf{X H 2}$ and $\mathbf{X H 4}$ products adsorb on the surface, blocking the diffusion process and their oxidation

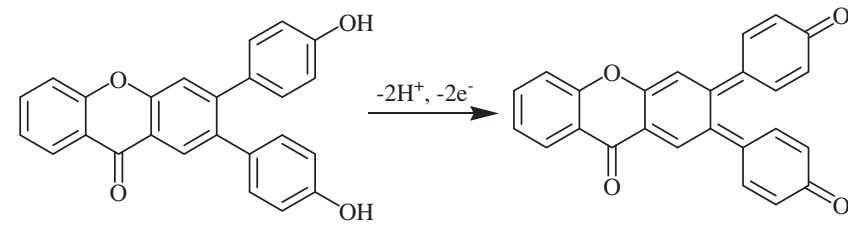

Scheme 2. Proposed oxidation of xanthone XH5 in phosphate buffer pH 7.4.

in the working surface electrode. Interestingly, derivative XH5 (two para-phenolic groups) undergoes only one irreversible oxidation peak $(0.56 \mathrm{~V})$, with a lower potential compared to analogues XH2 and XH4, indicating that the two phenolic groups were oxidized at the same potential. We can suggest that compound XH5 can be oxidized to a quinoide structure and, due to their instable nature, it decomposes in the voltammetric cell, making it difficult to observe the reduction peak (Scheme 2).

Cyclic voltammograms of the other derivatives XH3 and XH6-XH9 showed reversible oxidation peaks from 0.15 to $0.18 \mathrm{~V}$, corresponding to the catechol unit (3,4-dihydroxyphenyl substituent) oxidation (Fig. 1). This lower electrochemical anodic peak (generally lower than $0.50 \mathrm{~V}$ ) has already been reported in the flavonoid family on a glassy carbon electrode at neutral $\mathrm{pH}$ versus $\mathrm{Ag} /$ $\mathrm{AgCl}^{10,21-23}$ The results suggest that the D-catechol unit of the studied xanthones is more susceptible to oxidation than the Ecatechol moiety. Thus, compound XH3 (D-catechol, $E_{\mathrm{p} 1 \mathrm{a}}=0.16 \mathrm{~V}$ ) presented a lower oxidation peak than compound XH7 (E-catechol, $E_{\mathrm{p} 1 \mathrm{a}}=0.18 \mathrm{~V}$ ) and the same is observed for compounds XH6 and XH8 $\left(E_{\mathrm{p} 1 \mathrm{a}}=0.16 \mathrm{~V}\right.$ and $0.18 \mathrm{~V}$, respectively). Of note, compound XH9 (two catechol groups) showed the lowest potential oxidation peak at $0.15 \mathrm{~V}$ (Scheme 1). Such low oxidation potential and their effectiveness to donate hydrogen atoms, make XH9 a highly potent antioxidant with the most powerful reducing ability. ${ }^{24}$ In this regard, it is shown that, among all the xanthones under study, XH9 is the only derivative which can repair the $\alpha$-tocopheroxyl radical thereby restoring $\alpha$-tocopherol. ${ }^{8}$ Overall, these results are consistent with our previous studies on the electrochemical behavior of flavones and 2-styrylchromones, indicating that a higher number of hydroxyl groups correspond to a lower anodic potential peak of the catechol unit. ${ }^{25}$ 

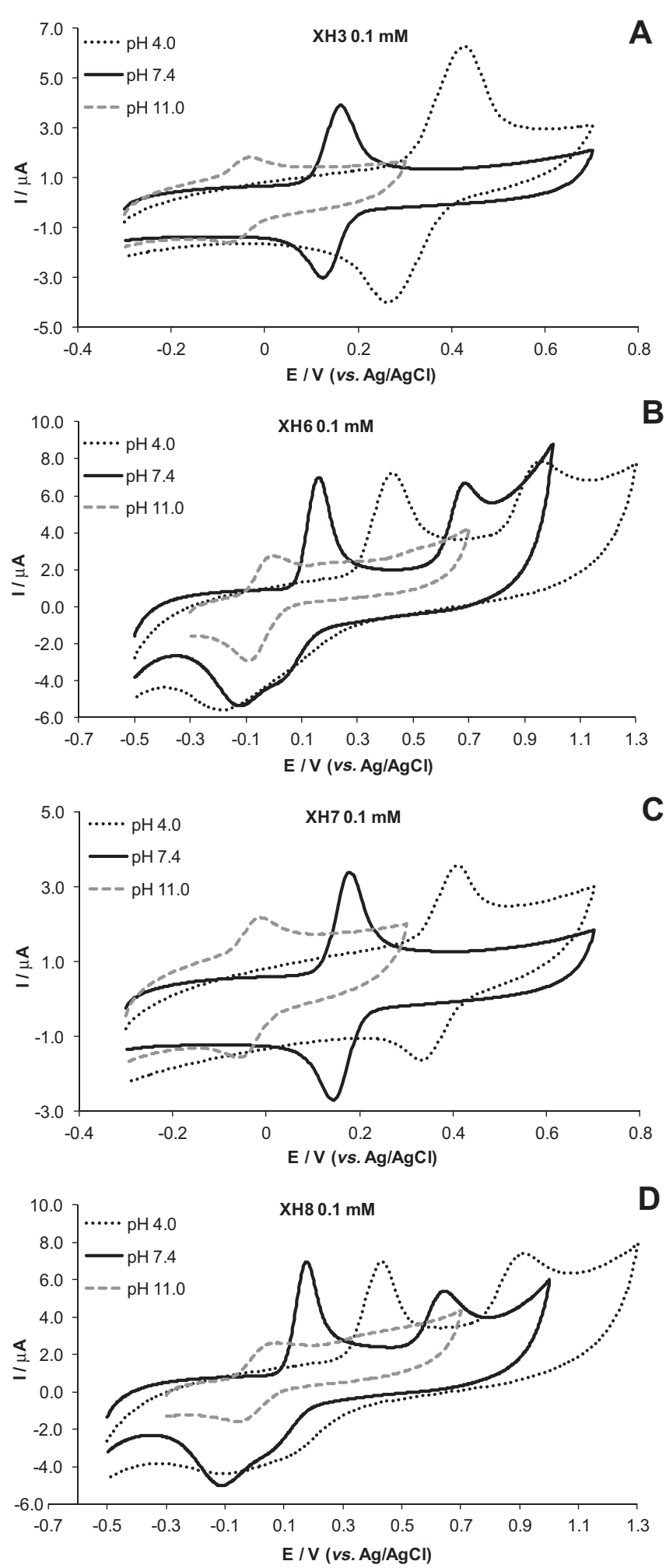

Figure 1. Cyclic voltammograms of compounds XH3 (A), XH6 (B), XH7 (C), and XH8 (D) $0.1 \mathrm{mM}$ at $\mathrm{pH} 4.0,7.4$ and 11.0. Scan rate $100 \mathrm{mV} \mathrm{s}^{-1}$.

A second peak has been identified for derivatives XH6 $\left(E_{\mathrm{p} 2 \mathrm{a}}=0.69 \mathrm{~V}\right)$ and $\mathbf{X H 8}\left(E_{\mathrm{p} 2 \mathrm{a}}=0.65 \mathrm{~V}\right)$, corresponding to oxidation of the para-phenol unit. Taking into account the results already discussed for XH2 and XH4 and the lower potential value of XH8 comparing with the analogue $\mathbf{X H 6}$, it may be postulated that the oxidation of the D-phenol is more favorable than the E-phenol. The second oxidation peak of XH9 presented the lowest potential at $0.37 \mathrm{~V}$ (Scheme 1). In fact, the two peaks of this molecule can be associated with the two oxidation centers and can be correlated with the analogues XH3 and XH7. The lower anodic peak of XH3 $\left(E_{\mathrm{p} 1 \mathrm{a}}=0.16 \mathrm{~V}\right)$ compared with that of $\mathbf{X H 7}\left(E_{\mathrm{p} 1 \mathrm{a}}=0.18 \mathrm{~V}\right)$ supports our postulate that the first peak of xanthone XH9 corresponds to the D-catechol unit oxidation $\left(E_{\mathrm{p} 1 \mathrm{a}}=0.15 \mathrm{~V}\right)$ and the second peak corresponds to the E-catechol oxidation. However, Born et al. ${ }^{26}$ in their voltammetric studies of verbascoside, a compound also bearing two catechol moieties, concluded that these units oxidize at the same anodic potential $\left(E_{\mathrm{pa}}=0.19 \mathrm{~V}\right)$, at $\mathrm{pH} 7.4$ versus $\mathrm{Ag} /$ $\mathrm{AgCl}$. They could not establish a correspondence between the catechol oxidation and the oxidation products. In the same work, the catechol oxidation potential of two natural ortho-dihydroxyxanthones, mangiferin $\left(E_{\mathrm{pa}}=0.32 \mathrm{~V}\right)$ and 1,3,6,7-tetrahydroxyxanthone $\left(E_{\mathrm{pa}}=0.28 \mathrm{~V}\right)$ presented higher values than the ortho-dihydroxyxanthones XH3 and XH6-XH9, leading us to consider that our studied synthetic xanthones have structural features for promising antioxidant applications. ${ }^{26}$

A defined cathodic peak can be observed in the cyclic voltammograms of compounds $\mathbf{X H 3}$ and $\mathbf{X H 6}-\mathbf{X H 9}$, pointing to the reversibility of the oxidation of these catecholic compounds. Electrochemical reduction of compounds XH3 and XH6 is measured at lower potential values than their analogues $\mathbf{X H 7}$ and $\mathbf{X H 8}$, respectively, suggesting once more that the redox reaction occurs easier in the presence of a D-catechol unit compared to a E-catechol unit.

Analysis of the electrochemical parameters of the tested xanthones showed a similar behavior at $\mathrm{pH} 11.0$, in comparison to those discussed at pH 7.4 (Scheme 1). The defined oxidation peak of compound XH2 presented a similar (although lower) potential value $\left(E_{\mathrm{p} 2 \mathrm{a}}=0.38 \mathrm{~V}\right)$ than the analogue $\mathbf{X H 4}\left(E_{\mathrm{p} 2 \mathrm{a}}=0.40 \mathrm{~V}\right)$, and derivative XH5 presented a lower anodic peak at $0.37 \mathrm{~V}$. The low intensity current peaks (from -0.08 to $0.04 \mathrm{~V}$ ) presented in the cyclic voltammograms of compounds XH3, XH6-XH9 may be ascribed to the catechol unit oxidation, at $\mathrm{pH} 11.0$ versus $\mathrm{Ag} / \mathrm{AgCl}$ (Fig. 1). Indeed, the electrochemical studies of quercetin and catechin referred anodic potentials at 0.07 and $0.23 \mathrm{~V}$, respectively, at $\mathrm{pH}$ 8.0. ${ }^{17}$ At the same $\mathrm{pH}$, other authors observed a lower anodic potential of catechin at $0.16 \mathrm{~V} .{ }^{23}$ On the other hand and as expected, the oxidation peak of quercetin is shifted toward a less positive potential at $0.10 \mathrm{~V}$, raising the $\mathrm{pH}$ at $9.0{ }^{27}$ The second anodic peak is less pronounced and attributed to the oxidation of the paraphenol group of compounds $\mathbf{X H 6}$ and $\mathbf{X H 8}$ (Fig. 1). At pH 11.0, the highest catechol group oxidation peak was observed for compound XH9 at $0.12 \mathrm{~V}^{8}{ }^{8}$ Curiously, this compound exhibited two oxidation peaks, while hematoxylin, an important bioactive flavonoid having also two catechol units, presented only one anodic peak, both in acidic and basic $\mathrm{pH}$ values. ${ }^{18}$

No detectable reduction peaks were observed in the cyclic voltammograms of compounds $\mathbf{X H 2}$, XH4, and XH5, at pH 11.0 suggesting that the oxidation products undergo further irreversible chemical reactions. The cathodic signals of compounds XH3, XH6-XH9 are probably due to the catechol moiety and displayed reduction potential values of -0.12 to $-0.03 \mathrm{~V}$ (Scheme 1 ). Interestingly, it may be noted that a similar value of the reduction potential of XH9 at $\mathrm{pH} 11$ was estimated by a fast kinetic spectroscopy from the equilibrium observed during the electron transfer reaction between the Trolox ${ }^{\circledR}$ radical and the ionized XH9 species. $^{8}$

Further electrochemical studies were performed in the acidic medium at $\mathrm{pH} 4.0$ and a decrease in the $\mathrm{pH}$ value led to an increase of both oxidation and reduction peak voltages (Scheme 1). A distinct lower anodic peak observed at 0.41-0.48 V may be attributed to the catechol group oxidation of compounds XH3, XH6-XH9. These results are in agreement with the work developed by Kilmartin et al. ${ }^{28}$ where cyclic voltammetry was used to characterize the antioxidant properties of phenolic compounds commonly 


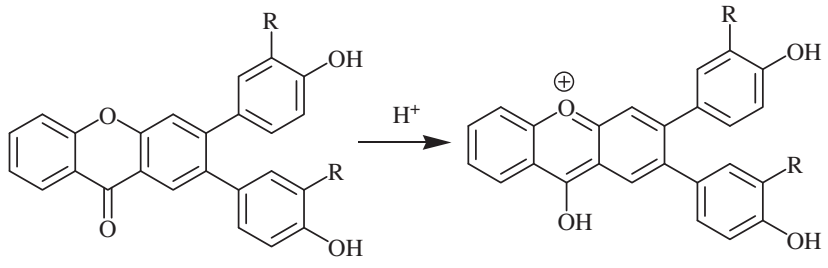

Scheme 3. Protonation of xanthones under acidic conditions.

found in wines, in model wine solutions at $\mathrm{pH}$ 3.6. Phenolic antioxidants with a catechol moiety in their structure exhibited oxidation peaks in the $0.36-0.47 \mathrm{~V}$ range. This study involved phenolic acids and flavonoids as caffeic and gallic acids, catechin and quercetin, with rutin presenting the higher potential value at about $0.47 \mathrm{~V}$. Similar potential values were obtained by other authors in the electrochemical oxidation of rutin, in acidic medium. ${ }^{29-31}$ Contrary to the results discussed before, at $\mathrm{pH} 4.0$ the anodic potential of compound XH3 $\left(E_{\mathrm{p} 1 \mathrm{a}}=0.42 \mathrm{~V}\right)$ was higher than the analogue $\mathbf{X H 7}$ $\left(E_{\mathrm{p} 1 \mathrm{a}}=0.41 \mathrm{~V}\right)$. This result can be explained by the xanthone carbonyl group protonation, under acid conditions, and the disappearance of the mesomeric stabilization effect of the heterocyclic oxygen atom on the D-ring phenoxyl radicals (Scheme 3 ).

The anodic peak detected at higher potentials (from 0.84 to $0.96 \mathrm{~V}$ ) may be ascribed to the para-phenol group oxidation (XH2, XH4-XH6, and XH8). p-Coumaric acid, a para-substituted cinnamic acid, presented a barely defined oxidation peak at 0.86 $\mathrm{V}^{28,32}$ whereas 4 '-hydroxyflavone and 4'-hydroxyisoflavone derivatives presented the same cyclic voltammogram profile. ${ }^{21}$ In addition, the isoflavonoid genistein presented a lower potential value $\left(E_{\mathrm{pa}}=0.80 \mathrm{~V}\right)$ than the flavonoid apigenin $\left(E_{\mathrm{pa}}=0.87 \mathrm{~V}\right)^{20}$ and a similar relationship is found in the anodic potentials of xanthones XH2 and XH4 $\left(E_{\mathrm{pa}}=0.84\right.$ and $0.87 \mathrm{~V}$, respectively), indicating that the D-phenol oxidation is more favorable than the E-phenol, at $\mathrm{pH} 4.0$ versus $\mathrm{Ag} / \mathrm{AgCl}$. The presence of two phenolic groups in the xanthone core (XH5) provides a single anodic peak, at $0.84 \mathrm{~V}$ (Scheme 1).

The absence of a cathodic peak in the cyclic voltammogram of para-phenolic derivatives $\mathbf{X H 2}$, XH4, and XH5 points to the irreversibility of the oxidation process (Scheme 1). This fact can be explained by subsequent oxidation chemical reactions or by the impossibility of these molecules to be reduced at the glassy carbon electrode. ${ }^{28}$ The well-defined cathodic peak of xanthones XH3 and XH6-XH9 varies depending on the position of the catechol moiety in the xanthone core. The $\mathrm{D}$-catechol derivatives were found to present lower reduction peak values $\left(\mathbf{X H 3}, E_{\mathrm{pc}}=0.27 \mathrm{~V}\right.$; XH6, $\left.E_{\mathrm{pc}}=-0.18 \mathrm{~V}\right)$ than the E-catechol analogues $\left(\mathbf{X H 7}, E_{\mathrm{pc}}=0.34 \mathrm{~V}\right.$; XH6, $E_{\mathrm{pc}}=-0.07 \mathrm{~V}$ ).

The electrochemical reactions of xanthones XH1-XH9 were further studied for various scan rates from 0.01 to $0.2 \mathrm{~V} \mathrm{~s}^{-1}$, recording the change of the peak current $\left(I_{\mathrm{p}}\right)$ and the potential peak values $\left(E_{\mathrm{pa}}\right)$, at $\mathrm{pH} 4.0,7.4$, and 11.0. Generally, by increasing the scan rate value, there was an increase in the oxidation peak current and a decrease in the reduction peak current. The absence of a cathodic peak already mentioned and the referred $I_{\mathrm{pa}}$ dependence with scan rate, indicates that compounds $\mathbf{X H 2}, \mathbf{X H 4}$, and XH5 undergo an irreversible electron transfer mechanism in the glassy carbon electrode surface. $^{33}$

The mechanism of the redox process can also be estimated by the ratio between the cathodic and anodic peak currents $\left(I_{\mathrm{pa}} / I_{\mathrm{pc}}\right)$ as well as by the peak potential separation $\left.\left(\Delta E_{\mathrm{p}}\right)\right)^{33-35}$ After a detailed observation of figure $1 \mathrm{~A}$ and $1 \mathrm{C}$ we can conclude that the peak current ratio $\left(I_{\mathrm{pa}} / I_{\mathrm{pc}}\right)$ tends to be closer to the unit for compounds XH3 and XH7 showing a complete electrochemical reversible process, for all studied $\mathrm{pH}$ values. ${ }^{35}$ For compounds XH6 and
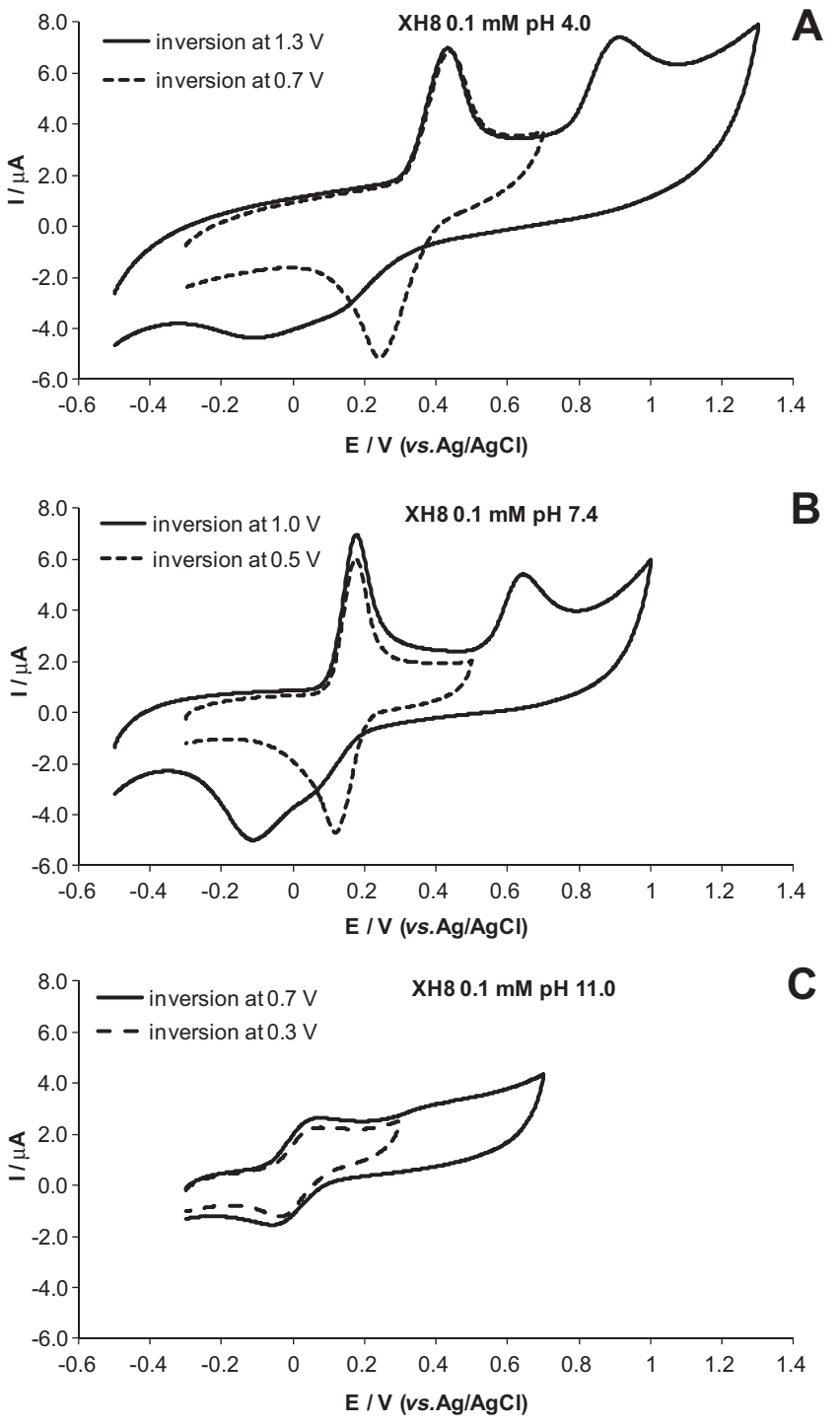

Figure 2. Cyclic voltammograms of compound XH8 $0.1 \mathrm{mM}$ : A (-) scan inversion at $1.3 \mathrm{~V}$; (-) scan inversion at $0.7 \mathrm{~V}, \mathrm{pH} 4.0$. B (-) scan inversion at $1.0 \mathrm{~V} ;(-)$ scan inversion at $0.6 \mathrm{~V}, \mathrm{pH} 7.4 . \mathrm{C}(-)$ scan inversion at $0.7 \mathrm{~V}$; (-) scan inversion at $0.3 \mathrm{~V}$, $\mathrm{pH}$ 11.0. Scan rate $100 \mathrm{mV} \mathrm{s}^{-1}$.

XH8, it was not possible to determine the $I_{\mathrm{pa}} / I_{\mathrm{pc}}$ ratio along with the scan rate interval probably due to the existence of a poorly defined reduction peak which stands in the same voltage of the lower cathodic peak. Meanwhile, when the potential scan of derivatives XH6 and XH8 was inverted before the second oxidation peak the voltammograms showed clear electroreduction peaks $\left(I_{\mathrm{pa}} / I_{\mathrm{pc}} \approx 1\right)$ (example in Fig. 2).

Considering the electrochemical behavior of xanthones XH3 and $\mathbf{X H 7}$ regarding the peak potential separation $\left(\Delta E_{\mathrm{p}}\right)$, one could observe that for $\mathrm{pH} 7.4$ and 11.0 , the $E_{\mathrm{pc}}-E_{\mathrm{pa}}$ values $\sim 30-35 \mathrm{mV}$ point to the involvement of two-electrons in the oxidation reaction on the glassy carbon electrode. The results suggest that the catechol moiety of the xanthone core is implied in a two-electron two-proton redox process, leading to the formation of orthoquinone-type intermediates. ${ }^{36}$ In acidic medium, the separation of the redox peak potentials $\Delta E_{\mathrm{p}}$ was $66 \mathrm{mV}$ and $159 \mathrm{mV}$ for $\mathbf{X H 7}$ and $\mathbf{X H 3}$, respectively. We can postulate that the mechanism behind the oxidation of $\mathbf{X H 7}$ involves the formation of a semiquinone intermediate which suffers disproportionation with formation of the ortho-quinone derivative and simultaneous regeneration of 

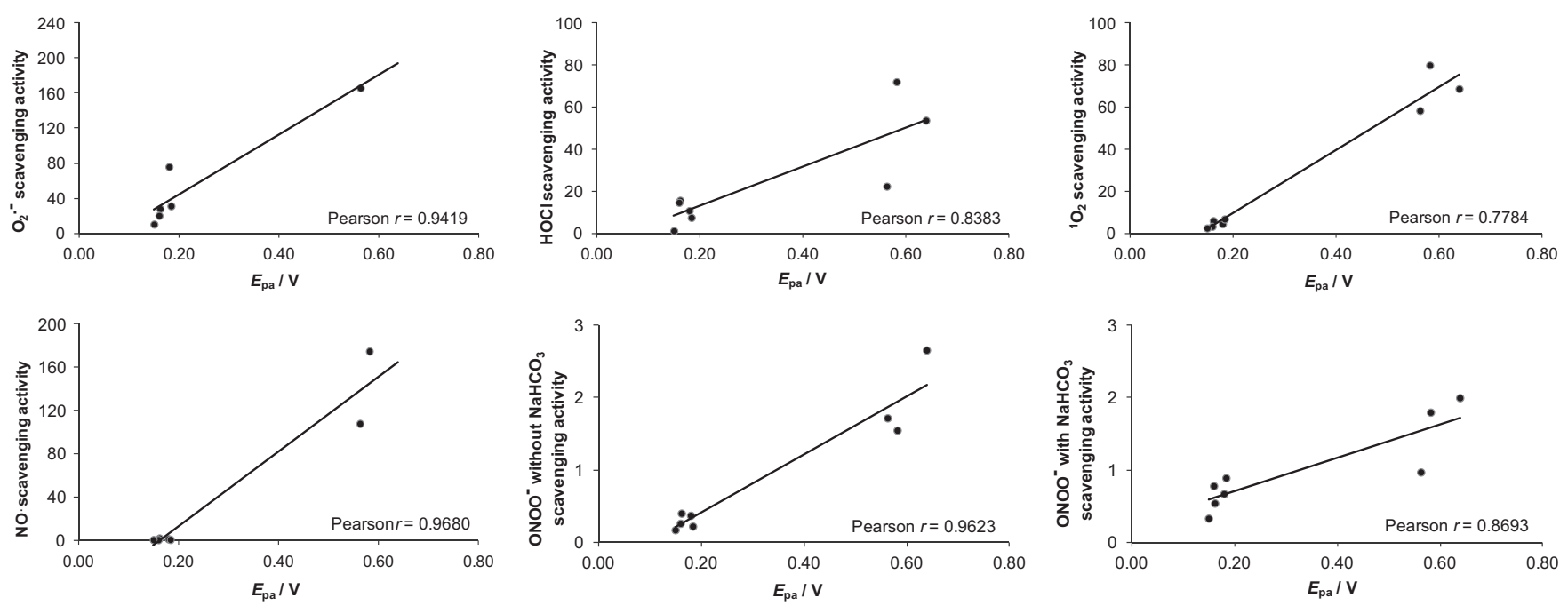

Scheme 4. Correlations between the $E_{\mathrm{pa}}$ at $\mathrm{pH} 7.4$ and the scavenging activity against ROS and RNS of hydroxy-2,3-diarylxanthones XH2-XH9.

XH7. These results are consistent with our previous report on the oxidation mechanism of 2-styrylchromones possessing a catechol moiety. ${ }^{25}$

When the potential scan was inverted before the second oxidation peak, the $\Delta E_{\mathrm{p}}$ value of xanthones XH6 and XH8 at pH 7.4 and 11.0 decreased to approximately $\sim 52-54 \mathrm{mV}$, corresponding to one-electron oxidation. Slightly changes occurred at $\mathrm{pH} 4.0$ showing high $\Delta E_{\mathrm{p}}$ values.

Based on the postulate that the electrochemical behavior of phenolic compounds is related to their antioxidant capacity, ${ }^{25-27,37}$ the comparison between the oxidation potentials under physiological conditions ( $\mathrm{pH} 7.4$ ) and the scavenging activity against ROS and RNS of the hydroxy-2,3-diarylxanthones XH2-XH9 is of great importance. In a previous work, we evaluated the scavenging activity of the hydroxy-2,3-diarylxanthones XH2-XH9 against several ROS, including superoxide radical $\left(\mathrm{O}_{2}{ }^{--}\right)$, hypochlorous acid $(\mathrm{HOCl})$, and singlet oxygen $\left({ }^{1} \mathrm{O}_{2}\right)$ and $\mathrm{RNS}$, including nitric oxide ('NO) and peroxynitrite anion $\left(\mathrm{ONOO}^{-}\right){ }^{7}$

Generally, the scavenging effect was related to the number and position of the hydroxyl substituents on the D- and E-rings of the xanthone core. In addition, compounds with a catechol motif presented a considerably higher effect than those lacking this structural feature as it can be confirmed by the $\mathrm{IC}_{50}$ values. In the present work, the correlations between the $E_{\mathrm{pa}}$ of the first peak at $\mathrm{pH} 7.4$ and the scavenging activity against ROS and RNS by hydroxy-2,3-diarylxanthones XH2-XH9 were studied by the Pearson correlation test (Scheme 4). Xanthones with lower oxidation potential values possess higher scavenging effects and the presence of a catechol group is an important structural feature for the antioxidant activity. Indeed, XH9, a xanthone with two catechol units, presented the lowest anodic potential voltage $\left(E_{\mathrm{pa}}=0.15 \mathrm{~V}\right)$ and proved to be the most effective scavenger for all the ROS and RNS tested (Scheme 4). Excellent correlations are observed for $\mathrm{O}_{2} \cdot{ }^{-}$, $\mathrm{NO}$, and $\mathrm{ONOO}^{-}$, as expected for scavenging reactions involving electron transfer mechanisms. Significant correlations are also found for $\mathrm{HOCl}$ and ${ }^{1} \mathrm{O}_{2}$, the highly reactive oxygen species which are known for scavenging mechanisms involving structural features. ${ }^{38}$

In conclusion, the cyclic voltammetric study allowed the electrochemical characterization of a group of hydroxy-2,3-diarylxanthones, in aqueous solution. Increases in the $\mathrm{pH}$ value led to a decrease in the anodic and cathodic peak voltages. Furthermore, the increase of the scan rate value promoted an increase in the anodic peak currents and a decrease in the cathodic peak currents. Cyclic voltammograms of compounds XH3, XH6-XH9 showed the permanent presence of a low oxidation peak attributed to the oxidation of the catechol group. The oxidation peak at higher potential values can be attributed to the phenolic groups. The electrochemical oxidation of $\mathbf{X H 3}$ and $\mathbf{X H 7}$ occurred in a complete reversible process, the number of electrons involved in the reaction being dependent on the structure and the $\mathrm{pH}$. The lower oxidation potentials of the hydroxy-2,3-diarylxanthones, when compared with structurally related phenolic compounds, the correlations obtained between these potentials and the scavenging ability, are good and direct indicators for the promising antioxidant properties claimed by these molecules.

\section{Acknowledgments}

Sincere thanks are expressed to Faculdade de Farmácia da Universidade do Porto, Universidade de Aveiro, Fundação para a Ciência e a Tecnologia (Portugal) and FEDER for funding the Organic Chemistry Research Unit (project PEst-C/QUI/UI0062/2011) and also to the Portuguese National NMR Network (RNRMN).

\section{References and notes}

1. El-Seedi, H. R.; El-Ghorab, D. M. H.; El-Barbary, M. A.; Zayed, M. F.; Göransson, U.; Larsson, S.; Verpoorte, R. Curr. Med. Chem. 2009, 16, 2581-2626.

2. Vieira, L. M. M.; Kijjoa, A. Curr. Med. Chem. 2005, 12, 2413-2446.

3. Pinto, M. M. M.; Sousa, M. E.; Nascimento, M. S. J. Curr. Med. Chem. 2005, 12, 2517-2538.

4. Jiang, D.-J.; Dai, Z.; Li, Y.-J. Cardiovasc. Drug Rev. 2004, 22, 91-102.

5. El-Seedi, H. R.; El-Barbary, M. A.; El-Ghorab, D. M. H.; Bohlin, L.; Borg-Karlson, A.-K.; Göransson, U.; Verpoorte, R. Curr. Med. Chem. 2010, 17, 854-901.

6. Pietta, P.-G. J. Nat. Prod. 2000, 63, 1035-1042.

7. Santos, C. M. M.; Freitas, M.; Ribeiro, D.; Gomes, A.; Silva, A. M. S.; Cavaleiro, J. A. S.; Fernandes, E. Bioorg. Med. Chem. Lett. 2010, 18, 6776-6784.

8. Morlière, P.; Patterson, L. K.; Santos, C. M. M.; Silva, A. M. S.; Mazière, J.-C.; Filipe, P.; Gomes, A.; Fernandes, E.; Garcia, M. B. Q.; Santus, R. Org. Biomol. Chem. 2012, 10, 2068-2076.

9. Santos, C. M. M.; Silva, A. M. S.; Filipe, P.; Santus, R.; Patterson, L. K.; Mazière, J.C.; Cavaleiro, J. A. S.; Morlière, P. Org. Biomol. Chem. 2011, 9, 3965-3974.

10. Teixeira, J. G.; Dias, C. B.; Teixeira, D. M. Electroanalysis 2009, 21, 2345-2353.

11. Bozal, B.; Uslu, B.; Özkan, S. A. Int. J. Electrochem. 2011, 1-17.

12. Heinze, J. Angew. Chem., Int. Ed. 1984, 23, 831-847.

13. Xanthones XH1-XH9 were synthesized according to previously reported procedures. See: Santos, C. M. M.; Silva, A. M. S.; Cavaleiro, J. A. S. Eur. J. Org. Chem. 2009, 2642-2660.

14. Experimental procedure: chemical reagents used for buffer solution preparation were of analytical grade, supplied by Sigma Chemical Co. (St. Louis, MO., USA). Stock solutions of XH1-XH9 5 mM were prepared in DMSO and further diluted 
in the supporting electrolytes (ionic strength of 0.2 ) at the final concentration of $0.1 \mathrm{mM}$, unless otherwise mentioned. Voltammetric experiments were carried out using an Autolab electrochemical system (Eco Chemie mode PGSAT 10). Before running the cyclic voltammetry experiments of our compounds control experiments were carried out to show that the solvent and supporting electrolytes have no influence on the potential region of interest. Data were acquired using the GPES (General Purpose Electrochemical System) software, version 4.9. The working electrode was a glassy carbon electrode $(\mathrm{GCE})(3.0 \mathrm{~mm})$. An $\mathrm{Ag} / \mathrm{AgCl}(\mathrm{KCl} 3 \mathrm{M})$ electrode and a carbon electrode were used as reference and auxiliary electrodes, respectively. Before use in electrochemical experiments and in order to obtain a clean renewed electrode surface, the glassy carbon working electrode was hand-polished with $0.075 \mu \mathrm{m}$ alumina aqueous slurry using a polishing cloth and washed with purified water. Cyclic voltammograms were obtained by a single cycle performed at a scan rate of $100 \mathrm{mV} \mathrm{s}^{-1}$, at room temperature. For the scan rate studies, the scanning speed varied from 10 to $200 \mathrm{~m} \mathrm{~V} \mathrm{~s}^{-1}$. Voltammetric scans were recorded in the voltage range between $-0.50 \mathrm{~V}$ and $1.20 \mathrm{~V}$ versus $\mathrm{Ag} / \mathrm{AgCl}$.

15. Masek, A.; Zaborski, M.; Chrzescijanska, E. Food Chem. 2011, 127 699-704.

16. Yakoleva, K. E.; Kurzeev, S. A.; Stepanova, E. V.; Ferorova, T. V.; Kuznetsov, B. A. Koroleva, O. V. Appl. Biochem. Microbiol. 2007, 43, 661-668.

17. Medvidović-Kosanović, M.; Šeruga, M.; Jakobek, L.; Novak, I. Croat. Chem. Acto 2010, 83, 197-207.

18. Zare, H. R.; Nasirizadeh, N. Electrochim. Acta 2011, 56, 3920-3925.

19. Sokolová, R.; Ramešvá, S.; Degano, I.; Hromadová, M.; Gál, M.; Žabka, J. Chem Commun. 2012, 48, 3433-3435.

20. Han, R.-M.; Tian, Y.-X.; Liu, Y.; Chen, C.-H.; Ai, X.-C.; Zhang, J.-P.; Skibsted, L. H. J. Agric. Food Chem. 2009, 57, 3780-3785.
21. Simić, A.; Manojlović, D.; Šegan, D.; Todorović, M. Molecules 2007, 12, $2327-$ 2340.

22. Brett, A. M. O.; Ghica, M.-E. Electroanalysis 2003, 15, 1745-1750

23. Janeiro, P.; Brett, A. M. O. Anal. Chim. Acta 2004, 518, 109-115.

24. Firuzi, O.; Lacanna, A.; Petrucci, R.; Marrosu, G.; Saso, L. Biochim. Biophys. Acta 2005, 1721, 174-184.

25. Gomes, A.; Fernandes, E.; Garcia, M. B. Q.; Silva, A. M. S.; Pinto, D. C. G. A. Santos, C. M. M.; Cavaleiro, J. A. S.; Lima, J. L. F. C. Bioorg. Med. Chem. Lett. 2008 16, 7939-7943.

26. Born, M.; Carrupt, P.-A.; Zini, R.; Brée, F.; Tillement, J.-P.; Hostettmann, K.; Testa, B. Helv. Chim. Acta 1996, 79, 1147-1158.

27. Samra, M. A.; Chedea, V. S.; Economou, A.; Calokerinos, A.; Kefalas, P. Food Chem. 2011, 125, 622-629.

28. Kilmartin, P. A.; Zou, H. A.; Waterhouse, L. J. Agric. Food Chem. 2001, 49, $1957-$ 1965.

29. Ghica, M.-E.; Brett, A. M. O. Electroanalysis 2005, 17, 313-318.

30. Malagutti, A. R.; Zuin, V. G.; Cavalheiro, E. T. G.; Mazo, L. H. Electroanalysis 2006, $18,1028-1034$

31. He, J.-B.; Wang, Y.; Deng, N.; Lin, X.-Q. Bioelectrochemistry 2007, 71, 157-163.

32. Janeiro, P.; Novak, I.; Seruga, M.; Brett, A. M. O. Anal. Lett. 2007, 40, 3309-3321.

33. Klingler, R. J.; Kochi, J. K. J. Phys. Chem. 1981, 85, 1731-1741.

34. Mabbott, G. A. J. Chem. Educ. 1983, 60, 697-702.

35. Kissinger, P. T.; Heineman, W. R. J. Chem. Educ. 1983, 60, 702-706.

36. Piljac-Žegarac, J.; Valek, L.; Stipčević, T.; Martinez, S. Food Chem. 2010, 121 820-825.

37. Lee, B. W.; Lee, J. H.; Lee, S.-T.; Lee, H. S.; Lee, W. S.; Jeong, T.-S.; Park, K. H. Bioorg. Med. Chem. Lett. 2005, 15, 5548-5552.

38. Estevão, M. S.; Carvalho, L. C.; Ferreira, L. M.; Fernandes, E.; Marques, M. M. B. Tetrahedron Lett. 2011, 52, 101-106. 